\title{
AC 2009-1054: AN INTERNATIONAL REPOSITORY FOR ENGINEERING AND TECHNOLOGY EDUCATION (IRETE)
}

\section{Nestor Osorio, Northern Illinois University}

Nestor L. Osorio is professor and subject specialist for science and engineering at Northern Illinois University, DeKalb, IL, e-mail: nosorio@niu.edu.

\section{Andrew Otieno, Northern Illinois University}

Andrew W. Otieno is associate professor at the Department of Technology, Northern Illinois University, DeKalb, IL, e-mail: otieno@ceet.niu.edu. 


\title{
An International Repository for Engineering and Technology Education (IRETE)
}

\begin{abstract}
Engineers work in settings that are dictated by global perspectives. This places a need for engineers who can operate seamlessly in global environments. A key component for the success of this seamless knowledge exchange is the development of information repositories for the engineering fields. E-Lis < http://eprints.rclis.org > is an example of such a repository for documents, published or unpublished, on librarianship, information science and technology. IRETE will be a repository totally focused to the world-wide community of scholars and teachers dedicated to engineering education. IRETE will operate with an administrative group under the leadership of a Principal Investigator or Director. Several working groups will focus on specific tasks such as: a technical group; a procurement and selection group; a metadata group; a publicity group. This paper presents a framework for the design and development of IRETE.
\end{abstract}

\section{Introduction}

The cornerstone of the US economy depends on innovation and creativity, backed by a well trained engineering workforce. Engineers work in settings that are dictated by global perspectives. As manufacturing continues to shift offshore, many US companies have been compelled to maintain a competitive edge in their global perspectives. This places a need for engineers who can operate seamlessly in global environments. It is imperative that colleges and universities worldwide must collaborate to develop strategies that provide the global perspectives and international experiences that will facilitate their graduates to perform effectively in this new world order. The role of information exchange in this effort is fundamental, as it provides the much needed avenues for knowledge dissemination. A key component for the success of this seamless knowledge exchange is the development of information repositories for the engineering fields.

In this paper, we would like to propose the development of a repository for information related to engineering and technical education. This International Repository for Engineering and Technology Education (IRETE) will serve a wider population of educators, students and the public, worldwide. We will present its importance, benefits to the profession and society, and the basic operating principles for this project. Two examples of successful subject repositories include the arXiv and E-Lis. The arXiv < http://arXiv.org >, a physics repository partially funded by the National Science Foundation, resides at Cornell University and is one of the largest in the world. Its main focus is physics but it also covers other related subjects. E-Lis < http://eprints.rclis.org $>$ is a repository for documents, published or unpublished, on librarianship, information science and technology. It is housed at CILEA, Consorzio Interuniversitario Lombardo per l'Elaborazione Automatica, Italy. E-Lis is run by a multinational group of volunteers. 
IRETE will be a repository totally focused on the world-wide community of scholars and teachers dedicated to engineering education. Educators around the world will have access to documents or bibliographic records that have not been properly entered into databases, catalogs or web engines such as Yahoo or Google. This information is essential for the improvement of teaching methods and the utilization of technology in the classroom. The benefits of a repository like IRETE go beyond engineering education; educators in other areas (the sciences, for example) would have access to information on curriculum development, course design, the recruitment and retention of students from ethnic groups and more.

IRETE will operate with an administrative group under the leadership of a Principal Investigator or Director. Several working groups will focus on specific tasks such as: a technical group; a procurement and selection group; a metadata group; a publicity group; etc. Finally, administrative procedures, a strategic plan, a plan for securing funding, and assessment strategies will be developed.

\section{Preserving the Literature of Engineering Education}

The literature of engineering education is complex and extensive. Powell ${ }^{1}$ describes the components of engineering education in a recent publication:

"Engineering education encompasses a number of categories, including students, faculty, practitioners and alumni, courses and programs, and assessment and evaluation. Topics relating to students include learning resources and practices, admissions and graduation requirements, advising, research opportunities, retention, and minority groups. Topics relating to faculty include specific teaching methods, publications and research methods, hiring, promotion, tenure, and strategies and tools used in the classroom. Practitioners and alumni address subjects relating to industry and collaborations. Assessment and evaluation refer to improving specific courses as well as overall engineering programs, plus distance learning, design, and ethics courses. Other topics include history of engineering education, and education and learning theory. Taken together they comprise the foundational subjects of engineering education."

Other topics not mentioned by Powell are, for example, the teaching of fundamental engineering concepts at the K-12 level, international education collaboration and standards, and lifelong learning.

The engineering education literature is produced in a variety of formats. As indicated by De Petro $^{2}$, articles in journals and articles in conference proceedings constitute the larger percentage, but books, book chapters, theses, reports, manuscripts and other formats are also represented. De Petro also states that engineering education is often underutlized; libraries do not have consistent collection development programs to acquire and maintain subscriptions of journals and conference proceedings, and the bibliographic records of the many contributions to the field are not found in the standard databases related to engineering or education. This problem which De Petro named a 'bibliographic deficiency' has often been a topic of discussion in some professional discussion groups of science/engineering librarians. The De Petro article is an accurate confirmation of the finding demonstrated by Osorio ${ }^{3,4}$ at two conferences of the American Society for Engineering Education. 
As indicated in a recent article by Jesiek et al. "an impressive expansion of engineering education has been underway since at least the early 2000s. This domain now boasts an infrastructure comprised of funding and granting agencies, publication outlets, conference venues, and academic units." This observation reinforces the findings of previous studies analyzing the literature of engineering education ${ }^{6,7,8}$ that demonstrated that the field is robust, with an increased emphasis on the utilization of research methodologies, and is international in coverage. It is an active scholarly field with participation from several professional societies, and with the production of a good number of dedicated journals and conference proceedings. The literature of engineering education also receives contributions from publications from almost all fields of engineering. In summary, its annual output is significant.

The International Repository for Engineering and Technology Education (IRETE), proposed here, would be a specialized and comprehensive database that would fill the gap or 'bibliographic deficiency' mentioned above. IRETE would be a database for all published documents related to engineering and technology education. The term 'published documents' includes articles in journals, conference papers, book chapters, and other publications that have gone through a peer review process and have been published by recognized professional publications. The main purpose is to create a repository database that would cover the literature of engineering and technology education internationally.

The proposed project for improving access to the literature of engineering and technology education has four specific goals:

i) to identify the body of literature from 1980 to the present that has been subject to a peer review process. This will include articles in journals, articles in conference proceedings, books, book chapters, reports, dissertations, and other documents;

ii) to construct a thesaurus for technology and engineering education, which will be used in the metadata of the database;

iii) to construct a database repository in an open-source environment such as EPrint, Fedora, or DSpace that will comply with the existing sophisticated technical requirements of cyberspace; including the allocation for high density data collection, images, graphs and other objects;

iv) to communicate to the target audience the availability of this dedicated engineering education database.

\section{Repositories}

An increasing number of academic and research institutions, as well as professional organizations, are building institutional repositories (IR) of electronic documents and objects. From the most respected universities (e.g., DSpace at MIT) to smaller technical institutions, IRs have been created to display the creativity and productivity of their researchers, faculty and students. IRs are found in many different frameworks; some are institutionally-oriented, while others are subject-oriented. Bailey ${ }^{9}$ provides the basic information needed to understand the nuts and bolts of an IR. The software available, how to self-archive documents, and the legal aspects of depositing articles are well covered on his web page. 
The number of IRs is continually growing. OpenDOAR - The Directory of Open Access Repositories <http://www.opendoar.org > includes 1,200 entries. Housed at the University of Nottingham, UK, it is recognized as an authoritative source and it is supported by the Open Society Institute (OSI). An example of academic IRs is the DSpace at MIT < ttp://dspace.mit.edu $>$. DSpace (which is featured in the January 2009 issue of PRISM ${ }^{10}$ ) is composed of fifty-eight communities representing many of MIT's departments and research centers. It is widely known for The MIT OpenCourse Ware - MIT OCW Archived Courses.

Subject-focused IRs are also abundant. The well-known arXiv at Cornell University < http://arxiv.org > which covers documents on physics, mathematics, non-linear science, computer science, quantitative biology, and statistics contains about half-a-million openlyaccessible articles. IRETE will fall in the category of a subject-focused repository. There are also some commercial enterprises offering now the capacity of building IRs, one example is BePress from Berkeley, CA.

\section{Educational and Social Benefits}

Several communities will benefit from having a specialized and dedicated open access bibliographic database of peer reviewed engineering and technology education documents. Researchers and librarians will benefit by having one database containing the bibliographic information of thousands of documents which can be used to support the findings for their engineering education project or to make bibliographies tailored to a specific topic. Teachers and curriculum developers at the K-12 level can use this database to find information about what works and what does not. For example, information about papers and documents explaining in detail how specific teaching labs can effectively be used in the classroom will be available.

College instructors at the undergraduate and graduate level will find numerous examples on how to improve their teaching and how to make modifications in the curriculum of their departments. Graduate students and teaching assistants will also learn about new approaches for teaching engineering topics.

Accreditation boards, university administrators, department heads, and teaching faculty can find valuable information about how to implement assessment programs in engineering and technology programs in this database. Students at all levels working on their research papers in technical related areas will find out, for example, how to utilize equipment in a lab environment.

The general public would also benefit. As indicated earlier, the formation of a diverse and highly-capable technical workforce is key for the healthy social and economic future of the country. This database can provide the general public information about efforts to improve technical education.

\section{Technical Functionality of IRETE Project}

IRETE will be a bibliographic database and repository developed using open-source software such as Fedora (Flexible Extensible Digital Object and Repository Architecture), EPrint, or DSpace with approximately 100,000 records - partially full-text - covering the period from 1980 
to the present. The major tasks for the development of this project are: 1 . Identification of documents, 2. Procurement of documents, 3. Thesaurus development, 4. Database development, and 5. Database Public Interface development.

The identification of publications related to engineering education represents an essential step. The publications to be included in the database are conference proceedings, journals, books, book chapters, and other publications. Articles from conference proceedings represented according to Osorio ${ }^{4}$ are: Annual Conference on Frontiers in Education; ASEE Annual Conference; SEFI Conference; International Conference on Engineering Education; SIGCSE Technical Symposium on Computer Science Education, International Conference on Engineering and Technology Education, INTERTECH; International Conference on Electrical and Computer Engineering, ICECE; and International Conference on Engineering Education ICEE.

Osorio's list covers more than 50 conference proceedings and many of these publications are not included in standard databases. The ASEE Regional conferences have never been indexed in any database. ASEE is divided into twelve regions, with each region holding annual sectional meetings. The work done by De Petro ${ }^{2}$ and Osorio ${ }^{3,4}$ has produced a list of dedicated engineering education journals. They also have identified other publications, most of them related to engineering fields, that publish on educational topics. The total combined list covers hundreds of titles. Some of them are: IEEE Transactions on Education, Chemical Engineering Education, ASEE Prism, International Journal of Electrical Engineering Education, International Journal of Engineering Education, European Journal of Engineering Education, Journal of Engineering Education, Journal of Professional Issues in Engineering Education, Engineering Science and Education Journal (ceased 2002), and International Journal of Mechanical Engineering Education. Standard engineering and educational databases have shown inconsistency in indexing articles on engineering education; missing articles or entire volumes are a persistent problem.

Databases and a variety of bibliographies would be used to identify books, book chapters, reports, dissertations, and other publications. These types of materials are also not consistently indexed by engineering or educational databases. It is estimated ${ }^{11}$ that the total number of documents to be identified from 1980 to present is nearly 100,000.

The procurement of documents will be a major effort for the completion of this project. Since most of the documents pre-1995 are in paper format, their procurement will require the expertise of document delivery services, the active participation of the director and co-directors by contacting several engineering, educational, and library-related professional organizations. The ability to find copies of hard-to-find publications will be an important task in this project. The logistics involved in uploading documents not only involve finding them, but also the process of getting the proper copyright permission for making them available. The members of the External Advisory Group would also be extremely valuable in this phase. The idea is to create a network of volunteers from several professional societies that would help in the finding of documents. This community involvement would also help in the dissemination process of the project.

A Thesaurus of terms for engineering education is not available. The development of such a thesaurus can be achieved by extracting the vocabulary terms by authors at the time of 
submission to conference proceedings and journals of the ASEE and SEFI societies. The collective subject vocabulary from these publications would be used as the base to construct a thesaurus for engineering and technology education. Hundreds of terms will be extracted from the documents, compiled, and organized.

For its technical functions, IRETE will utilize an operating system like the Flexible Extensible Digital Object and Repository Architecture (Fedora) and the metadata of records will follow a well established standard such as the Dublin standard or a modified form. IRETE will also adapt the most current protocol of the Open Archives Initiative (OAI). The flow of processing a document is shown in Figure 1:

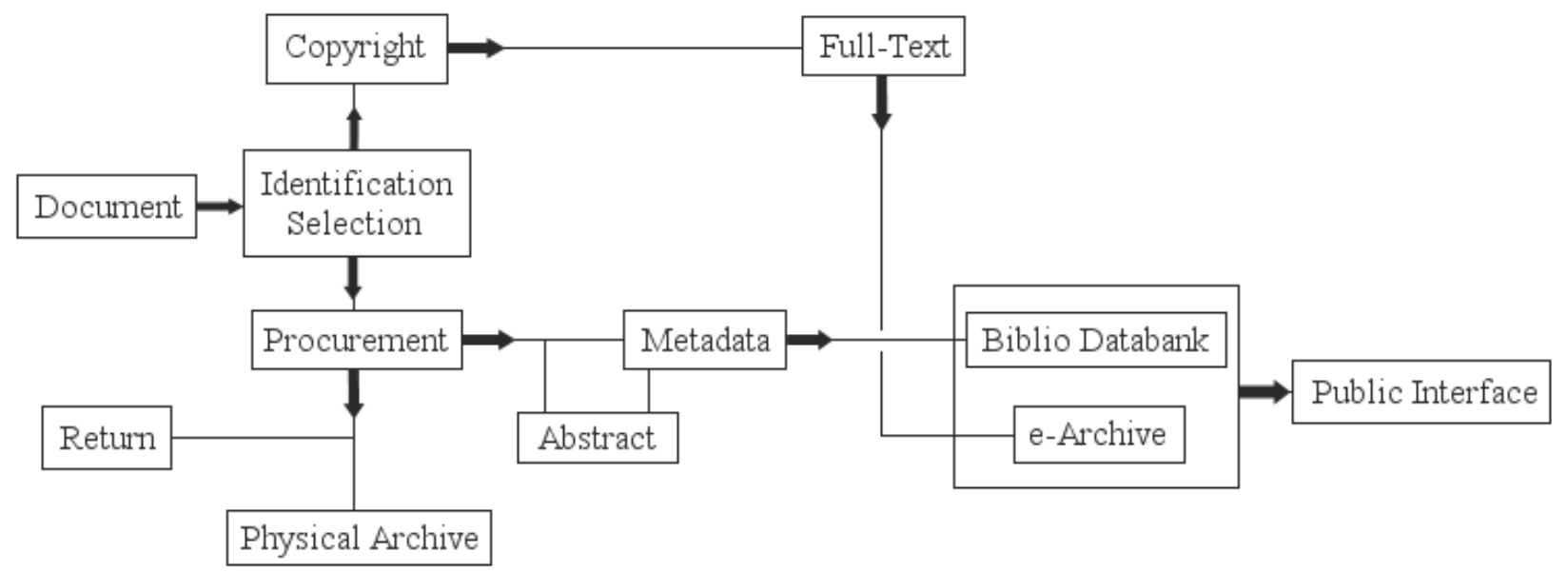

Figure 1

The database public interface will have the capability of searching several fields using Boolean operators (AND, OR, and NOT). Searchable fields will be: subject term, title, abstract, author, conference, and journal title. An "all fields" option will also be available. Limits to the search would be by: a range of years, type of document (article in journal, conference papers, book chapter, dissertation, report, etc.), and audience. A free keyword search capability would also be an option. Access by browsing the list of journals, conference proceedings and books will be also available.

The project would be divided into three phases:

Phase 1. Building the database architecture, creating the interface, developing a thesaurus, initial testing, beginning identification and collection of documents.

Phase 2. Continuing the identification and procurement of documents, loading metadata of documents without full-text, loading full-text documents and their metadata, testing and evaluation.

Phase 3. Open to the public, continuing loading metadata and full-text materials. At this time users will also be allowed to upload their documents using a proper registration and log-in system. 


\section{Administration, Assessment, and Funding}

A project of this significant magnitude would need a flexible organizational structure that would allow for the best utilization of technical and human resources to accomplish its goals. We envision having an executive group that, following a typical grant funding project, will have a director, one or two co-directors, a technical coordinator and a software expert. This group will serve as the Internal Management Team. This group will be involved in monitoring the progress of the project, its evaluation, and making recommendations for possible technical and other needs. Figure 2 shows the organizational chart.

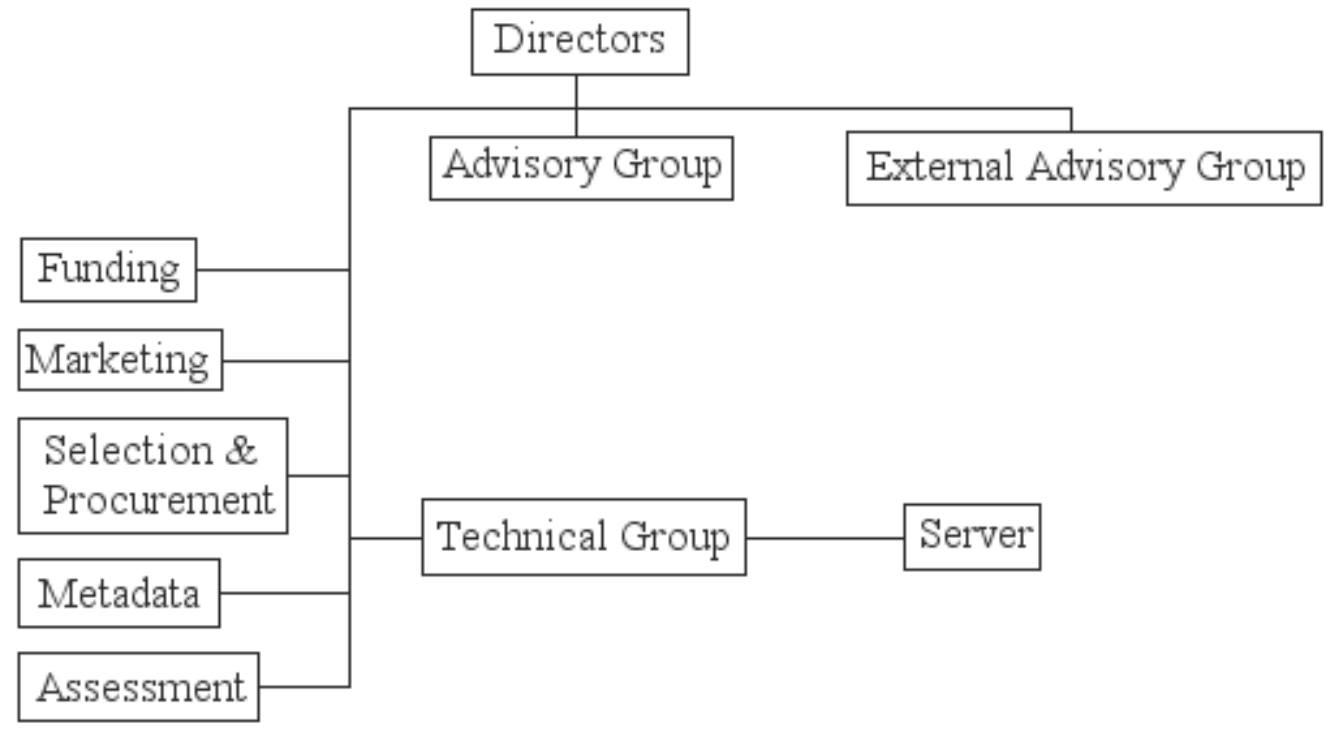

Figure 2

The principal directors and the two co-principal directors will oversee all operations of the project and make contact with people from other relevant organizations. Their responsibilities will include : contacting publishers and professional organizations in order to secure the usage of bibliographic data; obtaining the procurement of documents; identifying publications such as conference proceedings and journals as target sources for the database; working with other staff in the creation of a thesaurus; participating in the dissemination and evaluation processes of the project; obtaining required agreements to include the documents in the database; participating in testing the database; identifying other potential users for an initial pilot study of the database; overseeing the technical aspects of the project; be part of the Internal Consultation Team; and participating in the evaluation of the project. In addition, other staff will include a Project Technical Coordinator, a Database Technical Expert, a Metadata/Indexing Consultant, a Document Procurement Consultant; a Programmer, and Indexer/Data Entry staff.

The project will also have an External Advisory Group. This committee will be formed by members from the Engineering Library Division (ELD) of the American Society for Engineering Education (ASEE), Science and Technology Section (STS) of the Association of College and Research Libraries (ACRL), and the Engineering Division (ED) of the Special Library Association (SLA). Also, it will have three teaching faculty members, one member from the Information Systems Division (ISD) of ASEE, the two others from international organizations 
such as SEFI. This committee will advise on matters concerning the design and interface of the database, the procurement of documents (for example, older conference proceedings), the dissemination of the database to the targeted audience, and its evaluation.

Funding for repositories comes from diverse sources. Some repositories are built with the efforts of a dedicated group of volunteers while receiving server space from a friendly organization; such is the case of E-Lis ${ }^{12,13}$. Large repository projects are usually funded by non-profit foundations. It is also possible to receive funding from a government agency in the form of a grant and continuing the project with funds received from the private sector. IRETE as an educational international initiative could benefit from foundation grant awards from both private, national, and international organizations. The estimated ${ }^{11}$ cost for completing the first stage of this project is nearly $\$ 150,000$.

To ensure the success of the project, an assessment mechanism would be introduced in each of project components. This assessment would be done by the Internal Advisory Group and the External Advisory Group. Some key areas of continuing assessment are: 1. Reaching goals for selection and procurement of documents 2. Measuring the quality and effectiveness of the metadata 3. Determining the rate of securing copyright agreements. 4. Evaluating the quality of the interface and 5. Maintaining a flow of document uploading. In addition, surveys and focus groups will be other sources of information for assessment to be obtained from users.

\section{Conclusion}

New web technology has allowed for the development of repositories by academic and professional institutions. We have proposed the development of a repository that will focus on engineering education. In this paper, we have demonstrated the benefits of having a repository like IRETE. The functionality of IRETE has been presented, together with the technical aspects of building the repository. Based on the fact that it is designed to use open software, its cost effectiveness and ease of use could be a very significant.

The three major components of the proposed project are: 1. Build a bibliographic database covering the period from 1980 to 1995.

2. Build a bibliographic database covering the period from 1996 to the present (which will be Kept up-to-date).

3. Initiate the uploading of documents - that, according to copyright regulations, are, or can be made available to users for free access. Uploading retrospective full-text documents could start as soon as the infrastructure is completed. At the end of the second stage, it will also have the capability for self-uploading by authors. At stage three, it will be an important repository and the most complete bibliographic database for engineering education.

\section{Bibliography}

1. Powell, J. H. (2006). Engineering Education, in: Using the Engineering Literature, Bonnie A. Osif, editor, New York, Routledge, p. 269-285. 
2. De Petro, T. G. (2000). Engineering Education Periodicals and Proceedings: Increasing Awareness of and Access to the Literature. Proceedings of the 2002 ASEE Gulf-Southwest Annual Conference, Session IC3. [Available online] http://engr.louisiana.edu/asee/proceedings/IC3.pdf

3. Osorio, N. L. (1998). Engineering Education as Knowledge Discipline, American Society for Engineering Education, Annual Conference, Engineering Libraries Division, Poster Paper Session.

4. Osorio, N. L. (2005). What Every Engineer Should Know about Engineering Education, Proceedings of the 2005 Illinois/Indiana Sectional Conference, American Society for Engineering Education, D1-1. [Available online] http://eprints.rclis.org/archive/00008579/01/ASEE-IL-IN-2005-OSORIO.pdf

5. Jesiek, B. K., Newswander, L. K., and Borrego, M. (2009). Engineering Education Research: Discipline, Community, or Field? Journal of Engineering Education, Vol 98 no 1 p. 39-52.

6. Whitin, K. and Sheppard, S. (2004). Taking Stock: An Analysis of the Publishing Record as Represented by the Journal of Engineering Education, Journals of Engineering Education, Vol 93 no 1 p. 5-12.

7. Wankat, P. C. (2004). Analysis of the First Ten Years of the Journal of Engineering Education, Journals of Engineering Education, Vol 93 no 1 p. 13-20.

8. Osorio, N. L.; Osorio, M. A.. (2002). Engineering Education in Europe and the USA: An Analysis of Two Journals, Science \& Technology Libraries, Vol 23 no 1 p. 49-70.

9. Bailey, Charles W., (2009). Institutional Repositories, Tout de Suite, [Available online] http://www.digital-scholarship.org/ts/irtoutsuite.pdf

10. Boroughs, Don (2009). Millions Log In, Prism, Vol 18 no 5 p. 29-33.

11. Osorio, N. L., Otieno, A. W. (2008). The Technology and Engineering Education Database. Unpublished, 25 p. 12. De Robbio, A. and Sequeiros, P. (2007). Open archives for Library and Information Science: an international experience - Ogólnodostępne archiwa a informacja naukowa i biblioteczna - doświadczenia globalne., 2007 . In IV Ogólnopolska Konferencja EBIB : Internet w bibliotekach. Open Access, Toruń (Poland), 7-8 December 2007.

13. Morrison, H., Subirats C. I., Medeiros, N. and De Robbio, A. (2007). E-LIS: the Open Archive for Library and information Science, The Charleston Advisor, vol. 9, n. 1 p. 56-61(6). 